\title{
Atividade antibacteriana, antioxidante e tanante de subprodutos da uva
}

\author{
Antibacterial, antioxidant and tanning activity of grape by-product
}

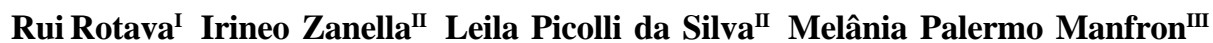 \\ Carla Speroni Ceron ${ }^{\text {III }}$ Sydney Hartz Alves ${ }^{\text {IV }}$ Ana Kátia Karkow ${ }^{\text {II }}$ João Paulo Aquino Santos ${ }^{\text {II }}$
}

\section{- NOTA -}

\section{RESUMO}

O objetivo neste trabalho foi determinar-se in vitro a atividade antibacteriana, antioxidante $e$ tanante de subprodutos da uva (Vitis vinifera) para seu aproveitamento como ingredientes alternativos na indústria avícola e na conservação de alimentos. Compostos polares foram extraídos da semente de uva desengordurada, em solução contendo acetona, água e ácido acético, resultando em $10,3 \%$ de rendimento de extrato de semente de uva desengordurada (ESUD). O ESUD apresentou alta atividade antibacteriana in vitro contra cepas de $\boldsymbol{S}$. aureus $\boldsymbol{e}$ E. coli, mas não contra cepas de Salmonella sp. A atividade antioxidante do ESUD foi comparável ao ácido ascórbico. A atividade tanante foi considerada baixa para a semente de uva e alta para o ESUD.

Palavras-chave: atividade antimicrobiana, atividade antioxidante, subprodutos da uva, taninos.

\section{ABSTRACT:}

The aim of this research was to determine in vitro the antibacterial, antioxidant and tanning activity from grape by-products (Vitis vinifera), for its use as alternative ingredients in the poultry industry and food conservation. Polar compound had been extracted of the defatted grape seed (SUD) in a solution with acetone, water and acetic acid, in the 90: 9.5: 0.5 ratio respectively, resulting in a yield of $10.3 \%$ of defatted grape seed extract (ESUD). ESUD has high antibacterial activity against strains of $\boldsymbol{S}$. aureus and $\boldsymbol{E}$. coli, but not against Salmonella sp. The antioxidant activities of the ESUD had comparable to the ascorbic acid. The capacity to bind proteins was considered low for the seed and high for the ESUD.

Key words: antimicrobial activity, antioxidant activity, grape by-products, tannins.

A indústria avícola brasileira enfrenta dificuldades para exportar carne de frango e derivados em função de restrições impostas por importadores, devido à presença de antibióticos nas dietas alimentares. Isso limita a utilização de promotores de crescimento tradicionais e estimula a pesquisa de alternativas para atender a essa demanda. Cresce também o interesse na utilização de compostos naturais, para aumentar a vida útil de produtos destinados à alimentação humana, de cosméticos e de medicamentos.

A atividade antibacteriana de compostos fenólicos da uva já foi estudada in vitro por BAYDAR et al. (2004), JAYAPRAKASHA et al. (2003) e RHODES et al. (2006). Além disso, esses compostos se constituem em fontes naturais antioxidantes em comparação aos sintéticos, largamente utilizados, e sem efeitos indesejáveis em processos enzimáticos ou orgânicos. (ARVANITOYANNIS et al., 2006)

\footnotetext{
IAssociação Sulina de Crédito e Assistência Rural (ASCAR), Associação Riograndense de Empreendimentos de Assistência Técnica e Extensão Rural (EMATER/RS). Travessa Piauí, 23, 95700-000, Bento Gonçalves, RS, Brasil. E-mail: ruirotava@hotmail.com. Autor para correspondência.

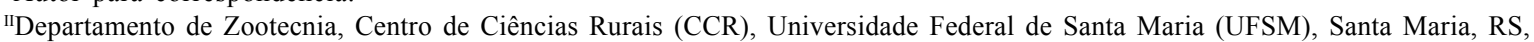
Brasil.

IIIDepartamento Farmácia Industrial, Centro de Ciências da Saúde (CCS), UFSM, Santa Maria, RS, Brasil.

${ }^{\mathrm{IV}}$ Departamento Microbiologia e Parasitologia, CCS, UFSM, Santa Maria, RS, Brasil.
} 
O objetivo neste trabalho foi determinar-se in vitro a atividade antibacteriana, antioxidante e tanante de subprodutos da uva (Vitis vinifera), para avaliar seu possível aproveitamento em dietas na indústria avícola e na conservação de alimentos.

Foram colhidas amostras de sementes de uva integrais (SUI) das cv. 'Tanat' e 'C. sauvignon', tendo seu óleo sido extraído, a quente, em prensa mecânica. A composição de ácidos graxos do óleo foi determinada pelo método de HARTMAN et al. (1973). As sementes de uva desengorduradas (SUD) foram moídas e maceradas com solução extratora de acetona, água e ácido acético, na proporção 90:9,5:0,5, respectivamente, ao abrigo de luz solar por 15 dias, com renovação de solvente aos sete dias, para extração de compostos fenólicos que, posteriormente, foram concentrados em rotoevaporador, conforme método adaptado de JAYAPRAKASHA et al. (2003). O extrato obtido denominou-se de extrato de semente de uva desengordurada (ESUD). A concentração inibitória mínima (CIM) e a concentração bactericida mínima (CBM) do ESUD, como solução etanólica a $20 \%$, foi determinada para cepas de Staphylococcus aureus ATCC 25923, Escherichia coli ATCC 25922 e do gênero Salmonella, pelo método de microdiluição em caldo, de NCCLS (1997). A atividade antioxidante do ESUD foi determinada pelo método fotocolorimétrico do 1,1difenil-2-picrilhidrazila (DPPH) de CHOI et al. (2002). Nas amostras de SUI, SUD e ESUD, foram determinadas a atividade tanante, a umidade, os sólidos solúveis e os sólidos não-tanantes, pelo método de análise quantitativa de tanino (SLTC, 1996).

A SUI prensada rendeu $13,4 \%$ de óleo, superior aos 10,2\% observados por CAO \& ITO (2003), mas dentro do rendimento esperado de 10 e $20 \%$. A análise da composição de ácidos graxos do óleo demonstrou conteúdo de $67,73 \%$ de ácido linoléico, $19,07 \%$ de ác. oléico, $8,02 \%$ de ác. palmítico e 4,19\% de ác. esteárico. Outros componentes são o ác. linolênico, ác. araquídico e ác. aracdônico com $0,45 \%$; $0,25 \%$ e $0,21 \%$, respectivamente. Esse conteúdo é parecido com o demonstrado por ARVANITOYANNIS et al. (2006). Os ácidos graxos têm importância energética e constituem componentes fundamentais de rotas metabólicas específicas. O ácido linoléico e, particularmente, seu isômero, ácido linoléico conjugado (CLA), são conhecidos por seus efeitos benéficos à saúde humana como efeito hipocolesterolêmico, estimulante do sistema imunológico, anticarcinogênico, sendo principalmente, antioxidante (SANHUEZA et al., 2002).

A quantidade de substâncias polares extraídas da SUD foi de 10,3\% de ESUD. Esse rendimento foi superior ao encontrado por BAYDAR et al. (2006) que obtiveram de 7,9 a 10,1\%, dependendo da cultivar e também foi superior aos $6 \%$ obtidos por JAYAPRAKASHA et al. (2003) que utilizaram metodologia parecida. No entanto, BAYDAR et al. (2004), em outro experimento, obtiveram rendimentos superiores a $15 \%$. As diferenças observadas podem ser decorrentes de metodologias de coleta de amostras e de extração, efeito de sazonalidade, diferentes cultivares e/ou estágio de maturação, localizações geográficas ou procedimentos de armazenagem (ensilagem).

A CIM do ESUD para 30 cepas de $\boldsymbol{E}$. coli apresentou média geométrica (MG) de $393,6 \mu \mathrm{g} \mathrm{ml}^{-1} \mathrm{e}$ para CBM a MG foi de $1039 \mu \mathrm{g} \mathrm{ml}^{-1}$, como mostra a tabela 1. Para 15 cepas de $S$. aureus, as médias foram de 206 e $452 \mu \mathrm{g} \mathrm{ml}^{-1}$, para CIM e CBM, respectivamente. Para 15 cepas de Salmonella sp. a CIM mostrou valores superiores a $2500 \mu \mathrm{g} \mathrm{ml}^{-1}$, não sendo avaliada, para esta bactéria, a CBM. Os resultados observados neste ensaio indicam atividade antibacteriana alta do ESUD contra $\boldsymbol{S}$. aureus e $\boldsymbol{E}$. coli, mas não contra Salmonella $s p$. Segundo SARTORATTO et al. (2004), valores de CIM, entre 50-500 $\mu \mathrm{g} \mathrm{ml}^{-1}$, são considerados de elevada atividade, sendo que, de 600 a $1.500 \mu \mathrm{g} \mathrm{ml}^{-1} \mathrm{e}$ acima de $1.500 \mu \mathrm{g} \mathrm{ml}^{-1}$, são considerados de média e baixa atividade, respectivamente.

O ESUD apresentou valores da CIM inferiores aos observadas por JAYAPRAKASHA et al. (2003), que utilizaram e compararam duas seqüências extratoras diferentes, uma cujo componente principal foi a acetona e outra com metanol, no qual acredita-se que o componente ativo contra $\boldsymbol{E}$. coli seja o ácido gálico. BAYDAR et al. (2004; 2006) mediram halos de inibição de crescimento provocado por compostos fenólicos, obtidos de diferentes extratores e também consideraram o ácido gálico presente o componente ativo contra bactérias. Asseguram que concentrações de 4 a 20\% de ESUD inibem o crescimento de bactérias GRAM positivas (mais facilmente) e negativas, concluíram que a maior concentração de compostos fenólicos da semente da uva pode ser utilizada para conservação de produtos na indústria de alimentos. TAGURI et al. (2004) consideram que polifenóis são mais ativos contra GRAM positivas, especialmente, o $\boldsymbol{S}$. aureus do que os GRAM negativos. Vários tipos de polifenóis, incluindo a catequina e seus derivados como a proantocianidina, têm atividade antibacteriana. A sensibilidade bacteriana depende da espécie testada, da sua estrutura molecular e diferentes metodologias utilizadas.

A concentração inibitória do DPPH (IC50) foi de 5,52 e $8,08 \mu \mathrm{g} \mathrm{ml}^{-1}$, respectivamente, para ácido ascórbico e ESUD. O ESUD apresentou percentual de 
Tabela 1 - Atividade antibacteriana do extrato de semente de uva desengordurada contra diferentes bactérias (\% de cepas inibidas).

\begin{tabular}{|c|c|c|c|c|c|c|}
\hline & \multicolumn{6}{|c|}{ Concentração inibitória mínima $\left(\mathrm{CIM}-\mu \mathrm{g} \mathrm{ml}^{-1}\right)$, número e porcentagem/acumulados de cepas inibidas } \\
\hline Bactéria & 78 & 156 & 312 & 625 & 1250 & $? 2500$ \\
\hline S. aureus ${ }^{1}$ & 0 & 9 & 6 & 0 & 0 & 0 \\
\hline$\%$ inibida/acumulado & 0 & $60 / 60$ & $40 / 100$ & 0 & 0 & 0 \\
\hline E.colí & 4 & 7 & 0 & 13 & 6 & 0 \\
\hline$\%$ inibida / acumulado & $13,3 / 13,3$ & $23,3 / 36,6$ & 0 & $43,3 / 80$ & $20 / 100$ & 0 \\
\hline Salmonella $s^{3}$. & 0 & 0 & 0 & 0 & 0 & 30 \\
\hline \multirow[t]{2}{*}{$\%$ inibida / acumulado } & 0 & 0 & 0 & 0 & 0 & 100 \\
\hline & \multicolumn{6}{|c|}{ Concentração bactericida mínima $\left(\mathrm{CBM}-\mu \mathrm{g} \mathrm{ml}^{-1}\right)$, número e porcentagem/acumulados de cepas inibidas } \\
\hline S. aureus ${ }^{1}$ & 0 & 0 & 7 & 8 & 0 & 0 \\
\hline$\%$ inibida / acumulado & 0 & 0 & $46,6 / 46,6$ & $53,4 / 100$ & 0 & 0 \\
\hline E.coli ${ }^{2}$ & 0 & 0 & 1 & 13 & 9 & 8 \\
\hline$\%$ inibida / acumulado & 0 & 0 & $3,2 / 3,2$ & $41,9 / 45,1$ & $29,1 / 74,2$ & $25,8 / 100$ \\
\hline Salmonella sp. & & & indeter & & & \\
\hline
\end{tabular}

${ }^{1}$ Foram utilizadas 15 cepas de S. aureus ${ }^{2}$ Foram utilizadas 30 cepas E.coli ${ }^{3}$ Foram utilizadas 30 cepas Salmonella.

inibição linear e crescente do DPPH que estabilizou em $94,26 \%$ na concentração de $200 \mu \mathrm{g} \mathrm{ml}^{-1}$, semelhante a do ácido ascórbico, com 96,58 \% de inibição para a mesma concentração. No entanto, valores de $25 \mu \mathrm{g}$ $\mathrm{ml}^{-1}$ de ESUD apresentam mais de $90 \%$ de inibição do radical livre DPPH. Compostos fenólicos, como flavonóides, triterpenos e taninos, são doadores de elétrons, portanto, antioxidantes naturais (GAO et al., 1999). Segundo BAKKALBASI et al. (2005), compostos fenólicos, particularmente, o flavan-3-ol tem comprovada capacidade de seqüestro de radicais livres, o que estimula a pesquisa e utilização desses compostos. Características como a inibição de enzimas e quelação de metais complementam os principais mecanismos antioxidantes COS et al. (2004).

Taninos são componentes vegetais originalmente utilizados para converter pele animal em couro, formando complexos estáveis com colágeno de pele bovina. Pode-se estimar essa habilidade por meio de metodologia especifica, denominanda atividade tanante, sendo expressa em percentual. A utilização de fontes vegetais como ingredientes de dietas de monogástricos fica condicionada ao tipo e concentração de taninos. Taninos são polifenóis metabólicos, com peso molecular ao redor de 500 e com habilidade de precipitar proteínas e gelatinas em solução. BENNICK, (2002) acredita haver alta correlação entre conteúdo de taninos e precipitação de proteínas, enzimas e peptídeos. Potencialmente, essas interações podem acontecer por ligação iônica ou covalente, interações hidrofóbicas ou pontes de hidrogênio, sendo $\mathrm{pH}$ dependentes.

A SUI, SUD e ESUD tiveram um total de 2,4; 3,3 e $50,6 \%$ de substâncias com atividade tanante e para substâncias não-tanantes, 16,1; 21 e 8,2\%, respectivamente. Essa capacidade é atribuída a compostos fenólicos (taninos condensados e hidrolisados) e corresponde somente aos compostos que tenham de três a sete unidades monoméricas condensadas. A quantidade de compostos insolúveis foi de 72,5; 69 e 35,8\% para SUI, SUD e ESUD, respectivamente. Essa fração é formada por fenóis muito condensados, acima de sete unidades e presentes na porção de fibra bruta. Para adstringência, os valores foram de 0,$15 ; 0,16$ e 6,17 , respectivamente, para SUI, SUD e ESUD, obtidas pelo quociente entre o valor de substâncias tanantes e não tanantes. De acordo com os resultados, o ESUD teve alta atividade tanante, fato não observado para a semente de uva cuja atividade foi considerada baixa.

O extrato de semente de uva desengordurada apresentou alta atividade antibacteriana in vitro contra cepas de $\boldsymbol{S}$. aureus e $\boldsymbol{E}$. coli, baixa atividade contra cepas de Salmonella sp. e atividade antioxidante comparável ao ácido ascórbico, fato que indica seu possível aproveitamento em dietas de frango de corte e na indústria de alimentos. A atividade tanante foi considerada baixa para a semente de uva e alta para o extrato de semente de uva desengordurada.

\section{REFERÊNCIAS}

ARVANITOYANNIS, I.S. et al. Potential uses and applications of treated wine waste. International Journal of Food Science and Technology, v.41, p.475-487, 2006.

BAYDAR, N.G. et al. Total phenolic contents and antibacterial activities of grape (Vitis vinifera L.) extracts. Food Control, v.15, n.5, p.335-339, 2004.

Ciência Rural, v.39, n.3, mai-jun, 2009. 
Determination of antibacterial effects and total phenolic contents of grape. International Journal of Food Science and Technology, v.41, p.799-804, 2006 .

BAKKALBAS, E. et al. Major flavan-3-ol composition and antioxidant activity of seeds from different grape cultivars grown in Turkey. European Food Research and Technology, v.221, n.6, 2005.

BENNICK, A. Interation of plant polyphenols with salivary proteins. Crititical Reviews Oral Biology \& Medicine, v.13, n.2, p.184-196, 2002.

CAO, X. et al. Supercritical fluid extraction of grape seed oil and subsequent separation of free fatty acids by high-speed counter-current chromatography. Journal of Chromatography A, v.1021, n.1, p.117124,2003 .

CHOI, C.W. et al. Antioxidant activity and free radical scavenging capacity between Korean medicinal plants and flavonoids by assay-guided comparison. Plant Science, v.163, p.1161-1168, 2002 .

COS, P. et al. Proanthocyanidins in Health Care: Current and New Trends. Current Medicinal Chemistry, v.11, n.10, p.1345-1359, 2004.

GAO, Z. et al. Free radical scavenging and antioxidant activities of flavonoids extracted from the radix of Scutellaria baicalensis Georgi. Biochimica et Biophysica Acta, v.1472, n.3, p.643650, 1999.
HARTMAN, L. et al. Rapid preparation of fatty acid methylesters from lipids. Laboratory Practice, v.22, n.8, p.475-476, 1973.

JAYAPRAKASHA, G.K. et al. Antibacterial and antioxidant activities of grape (Vitis vinifera) seed extracts. Food Research International, v.36, p.117-122, 2003.

NCCLS. National Committee for Clinical Laboratory Standards. Methods for dilution antimicrobial susceptibility tests for bacteria that grow aerobically. 3.ed. 1997. V.24, p.114-121. (Approved standard M7-A4, PA).

RHODES, P.L. et al. Antilisterial activity of grape juice and grape extracts derived from Vitis vinifera variety Ribier. International Journal of Food Microbiology, v.107, n.3, p. $281-286,2006$.

SARTORATTO, A. et al. Composition and antimicrobial activity of essential oils from aromatic plants used in Brazil. Brazilian Journal of Microbiology, v.35, p.275-280, 2004.

SLTC. Society of Leather Technologists and Chemist. Official methods of analysis. New York, 1996. 607p.

TAGURI, T. et al. Antimicrobial activity of 10 different plant polyphenols against bactéria causing food-borne disease. Biological Pharmaceutical Bulletin, v.27, n.12, p.19651969, 2004.

SANHUEZA, J.C. et al. Conjugated linoleic acid: a trans isomer fatty acid potencially beneficial. Revista Chilena de Nutricion, v.29, n.2, p.98-105, 2002. 